\title{
Left Ventricular Fractional Shortening
}

National Cancer Institute

\section{Source}

National Cancer Institute. Left Ventricular Fractional Shortening. NCI Thesaurus. Code C38020.

The fraction of the left ventricle diastolic dimension that is lost during systole; the measurement is calculated using the following formula: (end-diastolic dimension - endsystolic dimension) / end-diastolic dimension; the quotient is then multiplied by one hundred to be expressed as a percent. 